\title{
COMO? PALETAS MEXICANAS BRASILEIRAS?
}

\author{
HOW? MEXICAN PALETAS MADE IN BRAZIL?
}

\section{Daniela Maria Alves Chaud ${ }^{1}$ Edeli Simioni Abreu² Andrea Carvalheiro Guerra Matias ${ }^{3}$ Ana Carolina Oliveira ${ }^{4}$}

\begin{abstract}
Resumo: As informações sobre alimentação estão mais acessíveis e democráticas. As tendências alimentares são inspiradas por diversos fatores, mas sempre estão associados à moda, mídia e como forma de conjectura de um estilo de vida. Há pouco tempo, as grandes cidades brasileiras foram invadidas por uma nova mania: as paletas mexicanas, que, na verdade, não são "tão mexicanas". Esses sorvetes apresentam qualidades organolépticas marcantes, em virtude, entre outros fatores, ao alto teor de açúcar e, em alguns casos, de gorduras. A concepção gourmetizada e natural dessa iguaria, seu custo e as propriedades nutricionais são peculiares e, aparentemente, um modismo. Esse trabalho teve como objetivo conhecer a composição desses produtos, a partir das informações nutricionais contidas nos sites das empresas produtoras, bem como as suas peculiaridades e concepções. Apesar da conotação natural e gastronômica, alto valor calórico, gorduras (especialmente na versão recheada sabor brigadeiro) e elevadas quantidades de açúcares, foram encontrados, em média, por unidade: 207,2 Kcal; 38,4g de carboidratos; 3,9g de proteínas e 5,3g de gorduras. Uma rica ênfase na cultura mexicana, religiosidade e identidade visual marcante foram identificadas nos sites dos produtos pesquisados.
\end{abstract}

Palavras-chave: sorvetes; México; Brasil; antropologia cultural.

Abstract: Information about food is more accessible and democratic. Food trends are inspired by several factors but are always associated with fashion, media, and as a way to reflect a lifestyle. Recently, large Brazilian cities have been invaded by a new trend: Mexican paletas, which actually are not "Mexican." These ice cream pops have significant organoleptic qualities due to, among other factors, the high sugar content and, in some cases, fat. The gourmet and natural design of this delicacy, its cost, and nutritional properties are unique and apparently a passing fad. This study aimed to discover the composition of these products, based on the nutritional information available on the websites of the producers as well as their peculiarities and conceptions. Despite the natural and gastronomic connotations, high-calories, fat (especially in Brigadier flavor stuffed version), and high amounts of sugars were found at an average per unit of $207.2 \mathrm{Kcal} ; 38.4 \mathrm{~g}$ of carbohydrates; $3.9 \mathrm{~g}$ of protein, and $5.3 \mathrm{~g}$ of fat. A high emphasis on Mexican culture, religiosity, and visual identity fill the websites of the surveyed products.

Keywords: ice cream; Mexico; Brazil; cultural anthropology.

\footnotetext{
1 Doutora em Pediatria e Ciências Aplicadas à Pediatria - Universidade Federal de São Paulo - Unifesp, Brasil. Professor Adjunto da Universidade Presbiteriana Mackenzie - UPM, Brasil E-mail: daniela.chaud@mackenzie.br.

2 Doutora em Saúde Pública - Universidade de São Paulo - USP, Brasil. Professor Adjunto da UPM, Brasil. E-mail: edeli@mackenzie.br.

${ }^{3}$ Doutora em Saúde Pública - USP, Brasil. Professor Assistente da UPM, Brasil. E-mail: acgmatias@gmail.com.

4 Nutricionista Técnica do Programa Mackenzie de Qualidade de Vida (Qualimack) da UPM, Brasil. E-mail: ana.oliveira@mackenzie.br.
} 


\section{INTRODUÇÃO}

O que faz com que um alimento ou culinária vire tendência gastronômica ou se caracterize somente como um modismo?

As informações sobre alimentação estão mais acessíveis e democráticas do que há cinco ou dez anos. As tendências alimentares são inspiradas por diversos fatores, mas sempre estão associados à moda, mídia e, como forma de conjectura, de um estilo de vida. As mídias sociais aceleram a divulgação e democratizam as tendências. O que determina a manutenção de uma tendência é a influência de vários ensejos, como o espectro que pode alcançar (se é específico para chefs ou facilmente replicável por pessoas comuns), se pode ser produzido em escala e se pode ser associado a comportamentos regulares (SAX, 2014).

Atualmente, os sorvetes estão incluídos na dieta de muitas pessoas ao redor do mundo devido, em grande parte, às suas propriedades sensoriais (CONTRERAS et al., 2012). Esses produtos podem ser classificados de acordo com suas formulações, ou seja, à base de água ou de leite (ou derivados), sendo que estes últimos apresentam maior contribuição nutricional em termos calóricos, de proteínas, carboidratos, gorduras e minerais (especialmente cálcio) e vitaminas, como a $B_{2}$. Já, os a base de água podem ter seu valor nutricional alterado quando esta é substituída por suco de frutas (CONTRERAS et al., 2012).

No Brasil, existe uma variedade enorme de sorvetes, o que dificulta a sua classificação. Além da classificação supracitada, há os recheados (cuja composição dos recheios é igualmente variada), envoltos por camadas de chocolates de tipos variados (e estes, adicionados ou não de outros ingredientes, como as oleaginosas). Exceto os produtos à base de água, a gordura, seja a derivada do leite, seja a de origem vegetal, seja a produzida industrialmente, ou o blend de gorduras é um dos importantes componentes dos sorvetes cremosos, em virtude das suas propriedades físico-químicas e sensoriais (DAMODARAN; PARKIN; FENNEMA, 2008). Dentre todos os ingredientes, a gordura é o que mais varia de produto para produto, fato que interfere, sobremaneira, na sua qualidade nutricional (OLSEN; WHITE; WATSON, 2003).

Há que se ressaltar que cada tipo de gordura apresenta polimorfismo específico. $O$ comportamento térmico das gorduras durante o processamento do sorvete pode influenciar as propriedades do produto na fase intermediária e final (GRANGER, 2005). A quantidade típica das gorduras nos sorvetes está entre 10-16\% (ADAPA et al., 2000b). A composição bromatológica dos sorvetes, em termos de gorduras, depende das demandas de marketing e das condições de processamento; embora a qualidade do produto final dependa grandemente do processamento e dos parâmetros de congelamento, os ingredientes também apresentam importantes funções (ADAPA et al., 2000a).

O sorvete é classificado no grupo alimentar dos "Açúcares e Doces", apesar de uma possível contribuição nutricional em termos de micronutrientes, advinda da presença de frutas e leite (PHILIPPI, 2015). 
Ainda sobre os ingredientes, os carboidratos simples apresentam funções importantes nas qualidades organolépticas dos sorvetes. Açúcares são uma alternativa econômica interessante. Usualmente, blends contendo sacarose e glicose ou frutose são empregados como substitutos parciais da sacarose (ARBUCKLE, 2000). O dulçor das formulações também influencia no ponto de congelamento e descongelamento (DREWETT; HARTEL, 2007). Tais características interferem na viscosidade, na fase do produto descongelado (MILLER-LIVNEY; HARTEL, 1997).

No que concerne ao consumo de sorvetes, recentemente, estudo de Amaral et al. (2014), com 87 adolescentes, regularmente matriculados em escolas públicas, na cidade de Piracicaba, registrou a frequência de consumo entre 4 a 6 unidades, a cada 15 dias, por $11,5 \%$ dos indivíduos. Nesse mesmo estudo, os autores observaram que o consumo em outro momento, que não o momento das refeições, ocorre em $57,5 \%$ dos casos.

Acerca da alimentação e cultura entre os povos, Prado (2010), em seu artigo intitulado "Alimentação e Cultura na Espanha, no México e no Brasil: Reflexões Sobre as Constituições desse Campo Científico", registra o encontro entre cientistas de diversos países que ocorreu em 2008, na Universidade Estadual do Rio de Janeiro e ressalta a crescente busca por parte de profissionais da saúde, especialmente nutricionistas, por formação que considere a compreensão dos fenômenos alimentares, entendendo-os como necessariamente relativos e complementares ao campo nutricional e da saúde. Relata sobre a contribuição de Miriam Bertran Vilà, a qual apresenta um panorama da alimentação no México, particularmente sobre a cidade do México, a partir de uma perspectiva antropológica e considerando aspectos socioculturais e econômicos; reflete sobre o papel que fenômenos macrossociais exercem sobre o perfil nutricional atual em que a epidemia de obesidade é a característica principal. Cita Cascudo (1983), em sua contribuição histórica sobre alimentação, que a comida, a culinária e a cozinha identificam um grupo social e até uma nação, por meio de pratos culturalmente consumidos segundo horários, trabalho ou lazer, crenças, doenças, celebrações, conforme os significados e sentidos que thes são atribuídos. Ainda no tocante ao evento supracitado, devido às discussões culturais desses países, suas realidades históricas e os cenários epidemiológicos, a autora o classifica como nada mais contemporâneo.

Em ensaio semelhante, Espejel, Camarena e Saudoval (2014) tecem considerações sobre alimentos tradicionais do México. Os fatores históricos de cada povo e região vão criando características alimentares, que se baseiam nos componentes culturais e se encontram associados aos padrões de consumo dos indivíduos. Comenta, ainda, sobre a cozinha tradicional de diferentes povos, uso de ingredientes, épocas de consumo, entre outros. Exemplifica, entre outros casos, como o abacate é consumido em diversas partes do mundo, contudo a combinação de ingredientes e a forma de preparo conferem à guacamole um típico prato mexicano.

Recentemente, as grandes cidades brasileiras foram invadidas pela "mania" das paletas mexicanas, que foram criadas no México, na década de 1930, e chegaram ao Brasil 
em 2010. Inicialmente raro um quiosque era encontrado, contudo já se comentava sobre essa nova iguaria que se alastrou rapidamente em shoppings centers ou ruas, cujos elementos comuns são os que rementem à cultura mexicana, como o colorido, o sombreiro e o sol. No cenário da contemporaneidade e a característica da experience na qual há uma chamada coletiva para a experimentação, seja no âmbito do turismo, da aventura, dos investimentos pessoais, é interessante o dinamismo da introdução de novos produtos, a expansão desse ramo de atividade denuncia que o mercado é ávido para as novidades, as absorve rapidamente e, não raro, abandona-as com igual velocidade, o chamado modismo.

Instigados pela adoção desse novo hábito e ao ter a informação sobre a chamada de artigos com interface multifacetada em seus aspectos antropológicos, nutricionais e sociais, pareceu igualmente contemporâneo e oportuno conhecer um pouco mais sobre o provável modismo: os novos sorvetes de palito, as chamadas paletas mexicanas, consumidas por brasileiros, especialmente os residentes nas grandes cidades, e o simbolismo desse produto, pautado, ainda que aparentemente, na cultura mexicana. O objetivo geral deste trabalho foi conhecer melhor essa nova iguaria, por meio das informações disponíveis nos sites das empresas produtoras ou de enfoque gastronômico. O objetivo específico foi avaliar a informação nutricional presente nos rótulos de quatro sabores desses produtos.

\section{MÉTODOS}

Com o intuito de realizar o levantamento das informações das empresas produtoras de sorvetes do tipo paletas mexicanas, bem como de links veiculados na midia relacionados ao tema, foi utilizado o site de buscas Google, em 21/02/2014. Foram tabulados os dados da informação nutricional, bem como a concepção da empresa e dos produtos disponíveis. Nessa pesquisa, utilizou-se o descritor "paleta mexicana", sendo consideradas as 14 primeiras empresas, e os 10 primeiros links (veículos jornalísticos on line) com matérias gastronômicas que foram relacionados pelo site de busca. Como informações nutricionais, coletadas das empresas, consideraram-se quilocalorias (Kcal) fibras, gorduras e sódio.

\section{RESULTADOS}

A Tabela 1 apresenta os valores nutricionais médios de 32 sorvetes tipo paletas mexicanas, dos sabores Limão, Morango com Leite Condensado, Brigadeiro e Chocolate Diet. 
Tabela 1 - Média, valor máximo, valor mínimo e desvio-padrão de 32 sorvetes tipo paletas mexicanas (sabores Limão, Morango com Leite Condensado, Brigadeiro e Chocolate Diet)

\begin{tabular}{lcccccccc}
\hline & Kcal & Carboidratos & Proteínas & Gorduras & Gorduras & Gorduras & Fibras & Sódio \\
\hline Média & 207.2 & 38.4 & 3.9 & 5.3 & 2.73 & 0 & 0.7 & 50.9 \\
DP & 86,1 & 11 & 2,6 & 5,4 & 2,55 & 0 & 0,82 & 54,3 \\
Valor & 72 & 20 & 0 & 0 & 0 & 0 & 0 & 0 \\
Valor & 422 & 128 & 8 & 24 & 8,2 & 0 & 2,9 & 268 \\
\hline
\end{tabular}

$\mathrm{Na}$ Tabela 2, são apresentados os valores nutricionais individuais de sorvetes tipo paletas mexicanas, de acordo com os sabores: Limão, Morango com Leite Condensado, Brigadeiro e Chocolate Diet.

Tabela 2 - Média, valor máximo, valor mínimo e desvio-padrão de sorvetes tipo paletas mexicanas de acordo com os sabores: Limão, Morango com Leite

Condensado, Brigadeiro e Chocolate Diet

\begin{tabular}{|c|c|c|c|c|c|c|c|c|}
\hline & Kcal & $\begin{array}{l}\text { Carboidratos } \\
\text { (g) }\end{array}$ & $\begin{array}{l}\text { Proteínas } \\
\text { (g) }\end{array}$ & $\begin{array}{c}\text { Gorduras } \\
\text { Totais } \\
\text { (g) }\end{array}$ & $\begin{array}{c}\text { Gordura } \\
\text { saturada } \\
(\mathrm{g})\end{array}$ & $\begin{array}{c}\text { Gordura } \\
\text { Trans } \\
\text { (g) }\end{array}$ & $\begin{array}{l}\text { Fibras } \\
(\mathbf{g})\end{array}$ & $\begin{array}{c}\text { Sódio } \\
(\mathrm{mg})\end{array}$ \\
\hline \multicolumn{9}{|c|}{ SABOR LIMÃO ( $n=7)$} \\
\hline Média & 131,8 & 26,8 & 1,4 & 1,9 & 1,3 & 0 & 0,01 & 8,21 \\
\hline $\mathrm{DP}$ & 50,6 & 7,1 & 2,6 & 4,4 & 3,05 & 0 & 0 & 18,2 \\
\hline $\begin{array}{l}\text { Valor } \\
\text { Mínimo }\end{array}$ & 72 & 17,9 & 0 & 0 & 0 & 0 & 0 & 0 \\
\hline Valor Máximo & 224 & 36 & 7,2 & 12 & 8,2 & 0 & 0,03 & 49 \\
\hline \multicolumn{9}{|c|}{ SABOR MORANGO COM LEITE CONDENSADO $(n=12)$} \\
\hline Média & 204,7 & 48,3 & 3,2 & 3 & 1,7 & 0 & 0,7 & 36,2 \\
\hline $\mathrm{DP}$ & 33.1 & 26,3 & 0,84 & 1 & 0,84 & 0 & 0,4 & 13,7 \\
\hline $\begin{array}{l}\text { Valor } \\
\text { Mínimo }\end{array}$ & 161 & 32,9 & 2,3 & 1,5 & 0 & 0 & 0 & 0 \\
\hline Valor Máximo & 252 & 128 & 4,3 & 4,5 & 3,1 & 0 & 1,3 & 51 \\
\hline \multicolumn{9}{|c|}{ SABOR BRIGADEIRO $(n=10)$} \\
\hline Média & 301,9 & 41,2 & 6,8 & 11,8 & 5,2 & 0 & 0,7 & 101,6 \\
\hline DP & 50 & 7,4 & 1 & 4,4 & 2,1 & 0 & 1 & 41 \\
\hline $\begin{array}{l}\text { Valor } \\
\text { Mínimo }\end{array}$ & 250 & 30,9 & 4,3 & 7,2 & 4,4 & 0 & 0 & 268 \\
\hline Valor Máximo & 422 & 53 & 8 & 24 & 6,9 & 0 & 2,8 & 69,3 \\
\hline \multicolumn{9}{|c|}{ CHOCOLATE DIET (N=3) } \\
\hline Média & 77,6 & 14,3 & 2,5 & 1,1 & 0,5 & 0 & 2,1 & 40,8 \\
\hline DP & 1,1 & 2,9 & 2,9 & 0,1 & 0,3 & 0 & 0,69 & 38,9 \\
\hline $\begin{array}{l}\text { Valor } \\
\text { Mínimo }\end{array}$ & 77 & 16 & 0,8 & 1 & 0,2 & 0 & 1,7 & 0 \\
\hline Valor Máximo & 79 & 11 & 5,9 & 1,2 & 0,7 & 0 & 2,9 & 77,4 \\
\hline
\end{tabular}


As peculiaridades dos sorvetes tipo paletas mexicanas referentes ao conceito da empresa e do produto, do histórico e as curiosidades que envolvem esse novo produto são descritos no Quadro 1.

\section{Quadro 1 - Particularidades sobre as paletas mexicanas obtidas nos sites das 14 empresas produtoras selecionadas e/ou em sites com enfoques gastronômicos}

\begin{tabular}{|c|c|}
\hline Quanto ao histórico & $\begin{array}{l}\text { Religiosidade na América: oferendas de alimentos aos Deuses; } \\
\text { Neve proveniente de montanhas misturada ao mel, leite e frutas da época era } \\
\text { usada em cerimônia religiosa como oferenda, ensejando um ano de boa } \\
\text { colheita. Esse preparado era considerado um deleite para os Deuses; } \\
\text { Vindas do México; } \\
\text { Uma nova mania; } \\
\text { Inspiradas na cultura Mexicana; } \\
\text { Há muito tempo atrás em um vilarejo na península do México, vivia um povo } \\
\text { alegre e trabalhador... Que sofria com o superaquecimento do sol que a cada } \\
\text { dia aumentava seu poder de luz e calor, castigando os animais e queimando as } \\
\text { plantações. Foram ao alto do Chicén Itzá e as colocaram como oferenda ao } \\
\text { sol... Que ficou mais ameno... } \\
\text { Veio para unir o que há de melhor entre o Brasil e o México; } \\
\text { Surgiram após sucesso em eventos gastronômicos, como festivais de comida } \\
\text { de rua; } \\
\text { Uma das empresas precursoras iniciou atividade no final de } 2012 \text {, na região } \\
\text { Sul do Brasil (época de alta atividade econômica e turística). No final de } 2014 \text {, } \\
\text { a marca contava com } 61 \text { unidades em nove estados do país; } \\
\text { Uma outra rede registra venda mensal de } 26 \text { mil paletas por mês em apenas } \\
\text { uma das unidades; }\end{array}$ \\
\hline Quanto ao sabor & $\begin{array}{l}\text { Uma explosão de sabor; } \\
\text { Uma sobremesa deliciosa; } \\
\text { Conquistaram o paladar dos brasileiros; } \\
\text { Uma verdadeira tentação; } \\
\text { Surpreendente; } \\
\text { "No te preocupes com el sabor, produzimos nuestras paletas com muito } \\
\text { capricho y amor"; } \\
\text { Uma experiência saborosamente inesquecível; } \\
\text { De dar água na boca; } \\
\text { Caíram no gosto do paulistano; } \\
\text { Diversidade: agrada a todos os paladares; } \\
\text { Atende aos paladares mais exigentes; }\end{array}$ \\
\hline Quanto à nomenclatura & $\begin{array}{l}\text { Picolé mexicano; } \\
\text { Paleta mexicana; }\end{array}$ \\
\hline $\begin{array}{l}\text { Quanto ào processo de } \\
\text { produção }\end{array}$ & $\begin{array}{l}\text { Fabricadas em um processo natural e artesanal; } \\
\text { Sem conservantes; } \\
\text { Receita aparentemente simples, contudo, o preparo requer arte, técnica; } \\
\text { Produzidas por chefs; }\end{array}$ \\
\hline Quanto aos ingredientes & $\begin{array}{l}\text { Feitas à base de frutas frescas; } \\
\text { Selecionados (diferenciados); } \\
\text { De excelente qualidade; } \\
\text { Nada de produtos químicos; } \\
\text { Sem corantes; } \\
\text { As melhores matérias-primas; } \\
\text { Fórmulas exclusivas; }\end{array}$ \\
\hline Classificados como & $\begin{array}{l}\text { Frutados; } \\
\text { Recheados; } \\
\text { Premium; } \\
\text { Cremosas; } \\
\text { Linha alcoólica; } \\
\text { Para esportistas; }\end{array}$ \\
\hline
\end{tabular}




\begin{tabular}{|l|l|}
\hline & $\begin{array}{l}\text { Maior que picolé comum no Brasil; } \\
\text { lguarias; } \\
\text { O dobro do tamanho de um picolé tradicional; } \\
\text { Picolés gigantes, pesam até 120g; }\end{array}$ \\
\hline Quanto à qualidade sanitária & Controlada em todo o processo; \\
\hline Conceitos & $\begin{array}{l}\text { Divertidas; } \\
\text { Cliente se sente um Hermano; } \\
\text { Produtos diferenciados; }\end{array}$ \\
\hline Custo & $\begin{array}{l}\text { Menores preços: } \mathrm{R} \$ 6,00 \text { e } \mathrm{R} \$ 8,00 ; \\
\text { Maiores preços: } \mathrm{R} \$ 12,00 ;\end{array}$ \\
\hline Curiosidades & "Não te preocupes com a dieta, você pode vir de bicicleta”; \\
Lojas recriam atmosfera do México;
\end{tabular}

\section{DISCUSSÃO}

Um aspecto positivo das paletas mexicanas é o inquestionável uso de produtos in natura, especialmente das versões à base de água (ou suco de frutas). Quem já provou pode testemunhar a presença de sementes, "fiapos" e resíduos típicos dos vegetais frescos. Muitas vezes esses produtos são decorados com pedaços de frutas, como, por exemplo, nos sabores limão ou caipirinha, algumas empresas os decoram com uma rodela de limão, exibidos nas fan pages dos produtos. Há que se considerar que produtos congelados conservam, ainda que parcialmente, a qualidade nutricional em termos de micronutrientes e quando os vegetais não são coados (como parece ser o caso de algumas variações desses produtos), conservam melhor a qualidade nutricional presente nos gêneros in natura, seja em termos das fibras solúveis e insolúveis, seja em termos de micronutrientes.

Presume-se que a composição em termos de carboidratos dos produtos avaliados (Tabela 2) seja basicamente, no caso dos à base de água ou de suco de frutas, proveniente de sacarose, frutose e/ou glicose. Os cremosos (Tabela 2), por poder contar com leite em sua composição, podem conter, além dos carboidratos simples citados, a lactose e também em alguns casos, amido como carboidrato, usado devido à propriedade espessante. $O$ sabor limão, avaliado por Contreras et al. (2012), apresentou quantidade semelhante ao mesmo sabor avaliado no presente estudo, 28,5g por 100 gramas, em comparação à $26,8 \mathrm{~g}$ em 120 gramas - (para outros sabores, como manga, abacaxi, morango, kiwi, goiaba, entre outros, entre 24,2 a $31,8 \mathrm{~g}$ ). A quantidade de carboidrados nos produtos cremosos, tanto no presente estudo (Tabela 2) quanto no de Contreras et al. (2012) também se assemelhou.

Essa caracteristica nutricional, de significativa presença de açúcares, pode se sobrepor aos benefícios das vitaminas, minerais e fibras presentes nos ingredientes in natura. Recentemente, a Organizaçao Mundial da Saúde (World Health Organization, 2015) reviu a recomendação anterior para consumo de açúcares, que passou de $10 \%$ para $5 \%$ do consumo enérgético diário. Essa ação vem ao encontro dos esforços de combater o crescimento da obesidade e doenças dentárias. Como açúcares estão incluídos a sacarose, a glicose e a frutose advindos do açúcar de mesa, mel e frutas. Dentro desse contexto, para uma necessidade diária de $2000 \mathrm{kcal}$, o consumo não poderia ser superior a $100 \mathrm{kcal}$, que 
representam $25 \mathrm{~g}$ de açúcares. Considerando que parte signicativa dos carboidratos desses produtos são açúcares livres (amidos são geralmente utilizados como aditivos e administradas em pequenas quantidades), as paletas estudadas (exceto a versão diet ou zero) apresentam valores que provavelmente superam essa recomendação em apenas uma unidade; sabor limão $26,8 \mathrm{~g}(\mathrm{n}=7)$, sabor morango $48,3(n=12)$, sabor brigadeiro $(n=41,2)$ (Tabela 2).

Por outro lado, ainda referindo-se à presença de produtos in natura como ingredientes das paletas, dentre os produtos avaliados, com algumas exceções pontuais, não apresentaram representativas quantidades de fibras alimentares, ainda que estas estivessem presentes na maioria dos sabores avaliados. Segundo a Resolução 54/12 (BRASIL, 2012), para ser fonte de fibra devem apresentar mínimo de $3 \mathrm{~g}$ em 100g, ou 2,5g na porção. Os sabores Brigadeiro e Chocolate Diet apresentaram quantidade de fibras superior aos outros, possivelmente em virtude da maior quantidade de goma guar e da carboximetilcelulose, ambos componentes da classe das fibras alimentares adicionados ao produto, conforme consta nas especificações nutricionais destes. No entanto, a quantidade de fibras desses sabores não os enquadra em fonte de fibra. Em todas as informações nutricionais observadas não houve discriminação entre fibras solúveis e insolúveis, mas sim a menção "fibras", o que denota a quantidade de fibras totais. Contreras et al. (2012) avaliaram a quantidade de fibras em picolés produzidos e comercializados no México e encontraram valores igualmente insignificantes de fibras nos sabores à base de água (entre 0,03 a 0,8g). Também igualmente ao presente estudo, uma quantidade maior de fibras foi observada nos produtos cremosos, sendo que os valores variaram entre $0,31 \mathrm{~g}$ (sabor cookie) e a quantidade de $8,82 \mathrm{~g}$ (sabor castanha). Há que se considerar que o estudo de Contreras et al. (2012) avaliou a composição centesimal dos picolés e no presente estudo foi considerado o valor da porção de 120 gramas. A quantidade de fibras presentes nesses dois casos pontuais do presente estudo, cuja quantidades variaram entre 2,8 a 2,9g são superiores àquelas encontradas na mesma quantidade $(120 \mathrm{~g})$ de frutas, como laranja pera $(1 \mathrm{~g})$, abacaxi $(1,2 \mathrm{~g})$ e banana nanica $(2,28 \mathrm{~g})$. Parte desse conteúdo de fibras alimentares observado reflete a utilização de agentes estabilizantes e/ou emulsificantes. Muitas substâncias dessas classes de aditivos são carboidratos artificiais ou naturais com comportamento de fibras alimentares (LAJOLO et al., 2001).

Quanto às proteínas, o sabor com maior quantidade foi o Brigadeiro (Tabela 2), sendo que todos os produtos com esse sabor apresentavam-se na versão recheada. Possivelmente, essa quantidade advém das proteínas do leite. Como esperado, a quantidade de proteínas do único sabor à base de água (ou suco de frutas), ou seja, o sabor limão foi inferior quando comparado às outras versões.

Cabe salientar que sorvetes não substituem frutas in natura, ou seja, as paletas mexicanas estão contempladas, na pirâmide alimentar, no grupo dos açucares e doces (PHILIPPI, 2015). 
Uma única marca do sabor limão apresentou composição gordurosa muito superior às outras, inclusive no tocante à gordura saturada, certamente, os ingredientes utilizados nessa formulação diferem muito dos demais, contudo, não disponível nas informações nutricionais obtidas. Com exceção desse caso pontual, a quantidade de gorduras totais e saturadas se sobressaiu no sabor Brigadeiro (recheado).

Já, com relação à gordura trans, em todos os casos, a informação nutricional constava como "0" (zero). No caso da gordura trans, é previsto na portaria RDC n 54/12 que pode ser utilizado o claim (alegação) "zero gorduras trans", nos rótulos dos alimentos, desde que o alimento pronto para consumo atenda às seguintes condições: mínimo de $0,1 \mathrm{~g}$ de gorduras trans por $100 \mathrm{~g}$ ou $100 \mathrm{ml}$, ou porção e não apresente, no cômputo total de gorduras trans e saturadas, valor superior a $1,5 \mathrm{~g} \mathrm{em} 100 \mathrm{~g}$ ou $100 \mathrm{ml}$ de produto pronto (BRASIL, 2012). Há que se considerar que a legislação prevê que quantidades pequenas de gorduras trans não sejam apresentadas nos rótulos, contudo, essa questão é complexa, uma vez que o consumidor pode ter a falsa ideia de apresentar um consumo baixo de gorduras trans e esse, na verdade, ser elevado, quando porções grandes e frequentes de alimentos com quantidades (ainda que pequenas) de gorduras trans. A porcentagem do Valor Diário de ingestão (\%VD) de gorduras trans não é declarada porque não existe requerimento para a ingestão dessas gorduras. Ou seja, não existe um valor que deva ser ingerido diariamente. A recomendação é que seja consumido o mínimo. Para saber se o alimento é rico em gordura trans, deve-se verificar a quantidade por porção dessa substância nos rótulos de alimentos. Não se deve consumir mais de 2 gramas de gordura trans por dia. É importante, também, verificar a lista de ingredientes do alimento. Por meio dela, é possível identificar a adição de gorduras hidrogenadas durante o processo de fabricação do alimento (BRASIL, 2006).

Com relação ao sódio, considera-se que os produtos avaliados apresentam relativamente baixa quantidade, não se apresentando como um alimento de risco para hipertensos.

Ainda em relação às informações nutricionais, um ponto que deve ser considerado é o tamanho da porção. Segundo a RDC 359/03 (BRASIL, 2003), que aprova o regulamento técnico de porções de alimentos embalados para fins de rotulagem nutricional, porção "é a quantidade média do alimento que deveria ser consumida por pessoas sadias, maiores de 36 meses de idade, em cada ocasião de consumo, com a finalidade de promover uma alimentação saudável". Essa legislação também indica o tamanho da porção harmonizada e a medida caseira que deve ser utilizada na declaração de valor energético e demais nutrientes em função do alimento ou grupo de alimentos. Para item sorvetes individuais, a porção de referência é de $60 \mathrm{~g}$. No entanto, o peso da unidade média das paletas mexicanas é $120 \mathrm{~g}$, ou seja, duas porções de referência. Nesse caso, a mesma legislação, bem como a RDC 163/06 (BRASIL, 2006), preveem que o fabricante informe, além dos valores energéticos e nutricionais por unidade $(120 \mathrm{~g})$, indique o quanto esse valor difere da porção de referência $(60 \mathrm{~g})$, de modo que o consumidor seja esclarecido que aquela porção é maior. 
Um dos tipos de paletas pesquisados tem alegação de marketing esportivo e conta como ingrediente o suplemento amplamente consumido por praticantes de atividade física: whey protein. Nesse mesmo fabricante, há a alegação de que todos os produtos são $100 \%$ naturais, o que demonstra absoluto desconhecimento do conceito natural ou in natura artificial ou industrializado.

O apelo de marketing usado pelas empresas aborda questões culturais mexicanas, desde a antiguidade, sobre religiosidade, efeitos climáticos e, frequentemente, tentam aproximar ambas as culturas (mexicana e brasileira), sob o fio condutor dessa iguaria. Abordam, por exemplo, questões sobre a alegria do povo, a geografia e os contrastes de cores e elementos naturais típicos de países tropicais.

Quanto às qualidades sensoriais, as empresas não poupam elogios às suas produções, algumas chegam a ressaltar como uma "experiência explosiva", "inesquecível", "tentação", um convite à experimentação, ao deleite.

Essa nova concepção pareceu uma oportunidade para grandes, médios e pequenos (até aparentemente domésticos) empreendedores, atendendo a um ramo da economia em plena ascenção e, também, a um mercado de consumo que exige "coisas novas" e empreendedoras.

Um fato interessante é que as paletas mexicanas produzidas e comercializadas no Brasil não existem no México, uma contradição presente em todas as empresas pesquisadas, que enfatizam a cultura mexicana. As paletas mexicanas existentes no México são preparadas apenas com frutas e outros ingredientes simples, sem recheio ou combinações. O sabor mais consumido no México é o flor de hibisco e são comercializados em carrinhos por vendedores humildes em portas de escolas (aqui no Brasil conhecidos como sorveteiros) (MEGACURIOSO, 2015).

Sorvetes, além das inegáveis e inigualáveis propriedades organolépticas, podem contribuir para amenizar a sensação de calor dos países tropicais e podem ser produtos de qualidade nutricional. Os avanços nos estudos que viabilizem a melhoria da qualidade nutricional de sorvetes ainda são escassos. Dois deles são dignos de nota. Um deles se refere ao sorvete como um produto viável para micro-organismos probióticos (CORRALES; HENDERSON; MORALES, 2007); já, o outro estudo investigou a análise sensorial de sorvetes ricos em fibras com propriedades prebióticas, cujo resultado foi promissor (SALES et al., 2008).

\section{CONCLUSÃO}

Os valores nutricionais apresentados pelas empresas produtoras demonstraram que as paletas são de alta densidade calórica e, apesar da presença declarada de fibras, estas não estão em quantidades significativas. Produtos recheados, especialmente o sabor 
brigadeiro devem ter seu consumo parcimonioso, tendo em vista suas peculiaridades nutricionais.

A moda das paletas mexicanas movimentou o ramo econômico da alimentação fora do lar, e viabilizou pequenos, médios e grandes empreendimentos. Com concepção natural e gourmetizada, as paletas mexicanas possibilitaram aproximação da cultura mexicana e brasileira por meio da ambientação das lojas, do histórico e concepção dos produtos, muito embora os produtos disponíveis no Brasil não se assemelhem aos consumidos no México.

\section{REFERÊNCIAS BIBLIOGRÁFICAS}

ADAPA S. et al. Mechanisms of ice crystallization and recrystallization in ice cream: a review. Food Rev. Int., Essex v. 16, p. 259-271, 2000a.

ADAPA S. et al. Rheological properties of ice cream mixes and frozen ice creams containing fat and fat replacers. J. dairy sci., Champaign, v. 83, p. 2224-2229, 2000b.

AMARAL, R. C. et al. Estimates of self-reported dietary behavior related to oral health among adolescents according to the type of food. J Appl Oral Sci., Bauru, v. 22, n. 5, p. 416-25, 2014.

ARBUCKLE, W. S. Ice cream. 4. ed. Aspen: Chapman \& Hall, 2000.

BRASIL. RDC n 359 de 23 de dezembro de 2003. Aprova Regulamento Técnico de Porções de Alimentos Embalados para Fins de Rotulagem Nutricional. Diário Oficial da União, Brasília, 26 dez. 2003. Disponível em: <http://e-legis.anvisa.gov.br>.

RDC n 163 de 17 de agosto de 2006. Aprova o documento sobre Rotulagem Nutricional de Alimentos Embalados (Complementação das Resoluções-RDC no 359 e RDC nํ. 360, de 23 de dezembro de 2003). RDC n 163 de 17 agosto de 2006. Diário Oficial da União, Brasília, 17 agosto de 2006. Disponível em: <http://portal.anvisa.gov.br>.

Ministério da Saúde. Agência Nacional de Vigilância Sanitária. RDC no 54 de 12 de dezembro de 2012. Dispõe sobre o Regulamento Técnico sobre Informação Nutricional Complementar. Diário Oficial da União, Brasília 12 dezembro 2012. Disponível em: $<$ http://portal2.saude.gov.br>.

CASCUDO, L. C. História da Alimentação no Brasil. Belo Horizonte: Itatiaia, 1983.

CONTRERAS, E. L. et al. Chemical composition of ice pops produced in a microindustry from Hidalgo, Mexico. Rev. chil. nutr., Santiago, v. 39, n. 1, p. 62-69, 2012.

CORRALES, A.; HENDERSON, M.; MORALES, I. Sobrevivrencia de microorganismos probióticos en helado batido lactobacillus acidophilus y bifidobacterium lactis en helado batido. Rev. chil. Nutr., Santiago, v. 34, n. 2, p. 157-163, 2007. 
DAMODARAN, S.; PARKIN, K. L.; FENNEMA, O. R. Fennema química de los alimentos. 3. ed. Espanha: Acribia, 2008, 1154p.

DREWETT, E. M.; HARTEL, R. W. Ice crystallization in a scraped surface freezer. J. food eng., London, v. 78, p. 1060-1066, 2007.

ESPEJEL, J. E.; CAMARENA, D. M. J.; SANDOVAL, S. A. Alimentos tradicionales en Sonora, México: factores que influyen en su consumo. Innovar, Mexico, v. 24, n. 53, p. 127139, 2014.

GRANGER, C. et al. Influence of formulation on the thermal behavior of ice cream mix and ice cream. J. Am. Oil Chem. Soc., Champaign, v. 82, p. 427-431, 2005.

LAJOLO, M. L. et al. Fibra alimentaria em iberoamerica: tecnología y salud: obtención, caracterización, efecto fisiológico y aplicación en alimentos. São Paulo: Livraria Varela, 2001. 469p.

MEGACURIOSO. Contradição: paletas recheadas mexicanas não existem no México. 2015. Disponível em: <http://www.megacurioso.com.br/papo-de-bar/63185-contradicaopaletas-recheadas-mexicanas-nao-existem-no-mexico.htm>.

MILLER-LIVNEY, T.; HARTEL, R. W. Ice recrystallization in ice cream: interactions between sweeteners and stabilizers. J. dairy sci., Champaign, v. 80, p. 447-456, 1997.

OLSEN, D. W.; WHITE, C. H.; WATSON, C. E. Properties of frozen dairy desserts processed by microfluidization of their mixes. J. dairy sci., Champaign, v. 86, p. 1157-62, 2003.

PHILIPPI, S. T. Pirâmide dos alimentos: fundamentos básicos da nutrição. Barueri: Manole, 2015. 424p.

PRADO, S. D. Alimentação e Cultura na Espanha, no México e no Brasil: reflexões sobre a constituição desse campo científico. Physis, Rio de Janeiro, v. 20, n. 2, p. 353-355, 2010.

SALES, R. L. et al. Mapa de preferência de sorvetes ricos em fibras. Cienc. tecnol. aliment., Campinas, v. 28, p. 27-31, 2008.

SAX, D. The tastemakers: Why we're crazy for cupcakes but fed up with fondue. New York City: Public Affairs, 2014. 318p.

WORLD HEALTH ORGANIZATION. Guideline: Sugar intake for adults and children. Word Health organization. Geneva: WHO, 2015. 49p. Disponível em: <http://apps.who.int/iris/bitstream/10665/149782/1/9789241549028 eng.pdf?ua=1>. 